\title{
Local Role of $\mathrm{Ca}^{2+}$ in Formation of Veils in Growth Cones
}

\author{
Daniel J. Goldberg \\ Department of Pharmacology and Center for Neurobiology and Behavior, Columbia University, College of Physicians and \\ Surgeons, New York, New York 10032
}

\begin{abstract}
A previous study that used high-resolution video (VEC-DIC) microscopy to examine axonal growth cones of Aplysia giant neurons growing in culture had demonstrated that growth occurs by the extension of veils of membrane between filopodia and the subsequent morphological transformation of these veils, in place, into the swollen, organelle-filled central region of the growth cone and then into the cylindrical axon. The possible involvement of $\mathrm{Ca}^{2+}$ in this sequence of events was now examined using VEC-DIC microscopy. Reduction of $\left[\mathrm{Ca}^{2+}\right]_{0}$ from the normal level of 11 to $1.3 \mathrm{~mm}$ or below or the addition of $20 \mathrm{~mm} \mathrm{Co}{ }^{2+}$, which blocks $\mathrm{Ca}^{2+}$ channels, caused a large decrease in the area of immature veil (flat and with few organelles) in the growth cone within minutes. $\mathrm{Ba}^{2+}, 20 \mathrm{~mm}$, which flows well through $\mathrm{Ca}^{2+}$ channels, and 5 $\mu \mathrm{M}$ A23187, a $\mathrm{Ca}^{2+}$ ionophore, caused new immature veil to form in the presence of reduced $\left[\mathrm{Ca}^{2+}\right]_{0}$. Maturation of veil into central region was not inhibited by reduced $\left[\mathrm{Ca}^{2+}\right]_{0}$. In fact, the disappearance of immature veil was often the result partly, or entirely, of continued veil maturation in the absence of formation of new veil. The next step in maturation, conversion of the central region to cylindrical axon, was also probably not inhibited by reduced $\left[\mathrm{Ca}^{2+}\right]_{0} . \mathrm{Ca}^{2+}$ was microapplied to large growth cones that had lost their veils by exposure to reduced $\left[\mathrm{Ca}^{2+}\right]_{0}$. There was a strong tendency for the first, or only, incidence of veil formation to occur near the micropipette, the rest of the perimeter of the growth cone remaining quiescent. It is concluded that intracellular $\mathrm{Ca}^{2+}$ plays a role in veil formation and that the site of the $\mathrm{Ca}^{2+}$ dependent step is close to the site of veil formation. If this step is exocytosis, veil forms where there is net addition of membrane. Whether a change in $\left[\mathrm{Ca}^{2+}\right]_{1}$, rather than some other factor, normally directly triggers veil formation remains uncertain, but, if it does, then the site of formation, which will strongly influence the direction of axon growth, is probably determined by focal changes in $\left[\mathrm{Ca}^{2+}\right]_{i}$ within the growth cone.
\end{abstract}

A growing axon or dendrite is tipped by a growth cone. This region, which is structurally and functionally distinct from the rest of the neurite, is the site of events important for growth.

\footnotetext{
Received Aug. 18, 1987; accepted Dec. 3, 1987.

I am grateful to Mrs. AnnMarie Guzmán for excellent technical assistance and to Dr. Donald W. Burmeister for helpful discussions and for invaluable assistance in preparing the data for presentation. This work was supported by NIH research grants NS 14711 and NS 25161 and grants from the Stifel Paralysis Research Foundation and the William J. Mathtleson Foundation.

Correspondence should be addressed to Daniel J. Goldberg, Department of Pharmacology, Columbia University College of Physicians and Surgeons, 630 West 168th Street, New York, NY 10032.

Copyright $(C) 1988$ Society for Neuroscience $0270-6474 / 88 / 072596-10 \$ 02.00 / 0$
}

New membrane is added to the plasmalemma mainly in the growth cone (Bray, 1970; Griffin et al., 1981; Pfenninger and Maylié-Pfenninger, 1981), subunits for the elongation of cytoskeletal structures such as microtubules may also be added there (Letourneau and Ressler, 1984; Bamburg et al., 1986), and interactions of the growth cone with its immediate environment are probably important in determining the path of growth (Lctourneau, 1975b; Taghert et al., 1982; Caudy and Bentley, 1986). Many of the molecular details of how events in the growth cone cause and direct neurite growth are not known.

Recently, we used the technique of video-enhanced contrastdifferential interference contrast (VEC-DIC) microscopy to observe the living growth cones of giant neurons of the sea hare Aplysia californica in vitro (Goldberg and Burmeister, 1986). This high-resolution modification of DIC (Nomarski) microscopy (Allen, 1985) permits the detection of most of the intracellular organelles of the growth cone. We were able to describe in new detail, and thus with new insight, the sequence of events whereby new axon is formed at the growth cone. We observed that some of the diaphanous webs of membrane (veils) that protruded between borders formed by the rod-like projections of the growth cone (filopodia) underwent a process of maturation in place to form, eventually, new axon. Initially free of visible membranous organelles, the veil is gradually invaded first by small vesicles and then by larger organelles such as mitochondria from the swollen central region of the growth cone. The veil coincidently becomes more voluminous. When finally swollen and filled with organelles moving mainly randomly, the veil, and any neighbors undergoing a similar maturation, has been transformed into the new central region of the growth cone. Assumption of a cylindrical form and the conversion of most of the visible movement of membranous organelles from random to bidirectional fast axonal transport marks the transformation of this central region into mature axon.

We would now like to understand the factors that trigger the transformations from one stage of the sequence to the next. There is reason to suspect that $\mathrm{Ca}^{2+}$ is one such factor. Changes in the intracellular $\mathrm{Ca}^{2+}$ concentration $\left(\left[\mathrm{Ca}^{2+}\right]_{i}\right)$ of the growth cone have been reported to accompany changes in the rate of growth, although these results have been confusing, with one study reporting high $\left[\mathrm{Ca}^{2+}\right]$, in the growth cones of rapidly growing neurites (Connor, 1986), while another found $\left[\mathrm{Ca}^{2+}\right]_{\mathrm{i}}$ to go up when growth was halted by application of electrical stimulation or neurotransmitter (Cohan et al., 1987). When $\mathrm{Ca}^{2+}$ influx is enhanced in vitro, neurites of neuroblastoma cells grow faster (Anglister et al., 1982) and those of rat scnsory ncurons turn and grow towards a distant localized source of high $\left[\mathrm{Ca}^{2+}\right]$ (Gunderson and Barrett, 1980). The growth cone is probably rich in plasmalemmal $\mathrm{Ca}^{2+}$ channels (Grinvald and Farber, 1981; 
Freeman et al., 1985; MacVicar and Llinás, 1985; O'Lague et al., 1985) and in substrates for $\mathrm{Ca}^{2+}$-dependent protein kinases, including at least one whose transport from the cell body increases enormously during axon growth (Katz et al., 1985; Meiri et al., 1986). The formation of veils seems a likely step in the growth sequence for $\mathrm{Ca}^{2+}$ involvement for 2 reasons. First, increasing the extracellular $\left[\mathrm{Ca}^{2+}\right]\left(\left[\mathrm{Ca}^{2+}\right]_{0}\right)$ above normal has been reported to cause veil formation (Letourneau, 1975a, 1979; Anglister et al., 1982). Second, our VEC-DIC observations indicate that the veil is the precursor of the axon (Goldberg and Burmeister, 1986), and membrane for axon growth is probably added by exocytosis (Pfenninger and Maylié-Pfenninger, 1981). Since exocytosis in synaptic terminals (Katz, 1969) and at least some non-neuronal cells (Douglas, 1968) is regulated by $\mathrm{Ca}^{2+}$, it is reasonable to suspect an involvement of $\mathrm{Ca}^{2+}$ in veil formation. This issue has been examined in the experiments reported here by observing large growth cones of Aplysia neurons in vitro using VEC-DIC microscopy.

Filopodia delimit the possible directions of axon growth by defining the pathways for veil extension (Goldberg and Burmeister, 1986). But sometimes there are many filopodia, not all of which support veil extension (Goldberg and Burmeister, 1986). Preferential extension of veils along certain filopodia has been described in vivo and may be important in determining the direction of growth (Caudy and Bentley, 1986). Experiments reported here pertain also to the question of why veils form where they do on the growth cone.

\section{Materials and Methods}

Cell culture. Juvenile (2-10 gm) sea hares, Aplysia californica, were obtained from the Aplysia mariculture facility of the Howard Hughes Medical Institute at the Woods Hole Oceanographic Institute in Woods Hole, MA. Neurons were removed from the buccal ganglia and placed in culture as previously described (Schacher, 1985; Goldberg and Burmeister, 1986). Large and medium-sized neurons were used, with no attempt made to identify the individual neuron used in a particular experiment. Some cells were cultured in a 1:1 mixture of Aplysia hemolymph and modified L-15 medium (L-15 to which salts were added to approximate the ionic composition of sea water) (Schacher and Proshansky, 1983). Others were cultured in $100 \%$ modified L-15 medium and still others in homemade culture medium (GCM) designed to approximate the composition of modified L-15 but to lack the $\mathrm{SO}^{2-}{ }_{4}$ that causes $\mathrm{Ba}^{2+}$ to precipitate. GCM was used in all of the experiments involving $\mathrm{Ba}^{2+}$ and some involving $\mathrm{Co}^{2+}$. The composition of $\mathrm{GCM}$ was $450 \mathrm{~mm} \mathrm{Na}^{+}, 10 \mathrm{~mm} \mathrm{~K}^{+}, 11 \mathrm{~mm} \mathrm{Ca}^{2+}, 55 \mathrm{mM} \mathrm{Mg}^{2+}, 562 \mathrm{mM} \mathrm{Cl}^{-}$ $40 \mathrm{mM}$ D-glucose, 10\% MEM 100 $\times$ amino acids (GIBCO), 1\% MEM vitamins (GIBCO), $10 \mathrm{~mm}$ Hepes, $\mathrm{pH} 7.4$. Streptomycin $(0.1 \mathrm{mg} / \mathrm{ml})$ and penicillin $(200 \mathrm{U} / \mathrm{ml})$ were added to all solutions used for culturing. In experiments involving the use of trifluoperazine (TFP) or compound R24571 (calmidazolium), the mixture of hemolymph and modified L-15 was used throughout the experiment. Otherwise, either $100 \%$ modified L- 15 or $100 \%$ GCM was used throughout or the neurons were initially left overnight in the hemolymph-modified L-15 mixture and then transferred to pure modified L-15 or pure GCM a few hours before the start of the experiment. When either of these latter solutions was used from the outset, the dish was first conditioned by exposing it to pure hemolymph for several hours.

Video microscopy. Neurons were used within a day of placement in culture. VEC-DIC microscopy using an inverted light microscope was performed as previously described (Goldberg and Burmeister, 1986). For those experiments that required the use of a micropipette, a condenser with a working distance of $7 \mathrm{~mm}(0.63 \mathrm{NA})$ was used rather than the normal short working distance condenser (1.4 NA), resulting in somewhat lower resolution. Also, a $15 \times$, rather than a $25 \times$, ocular was used to project the image to the TV camera when the former condenser was used because it resulted in less mottle in the TV image. Magnification of the image on the TV monitor in these cases was $4140 \times$, rather than the $7380 \times$ obtained with the $25 \times$ ocular, but veils were still clearly visible. All tape recordings were made in real time.

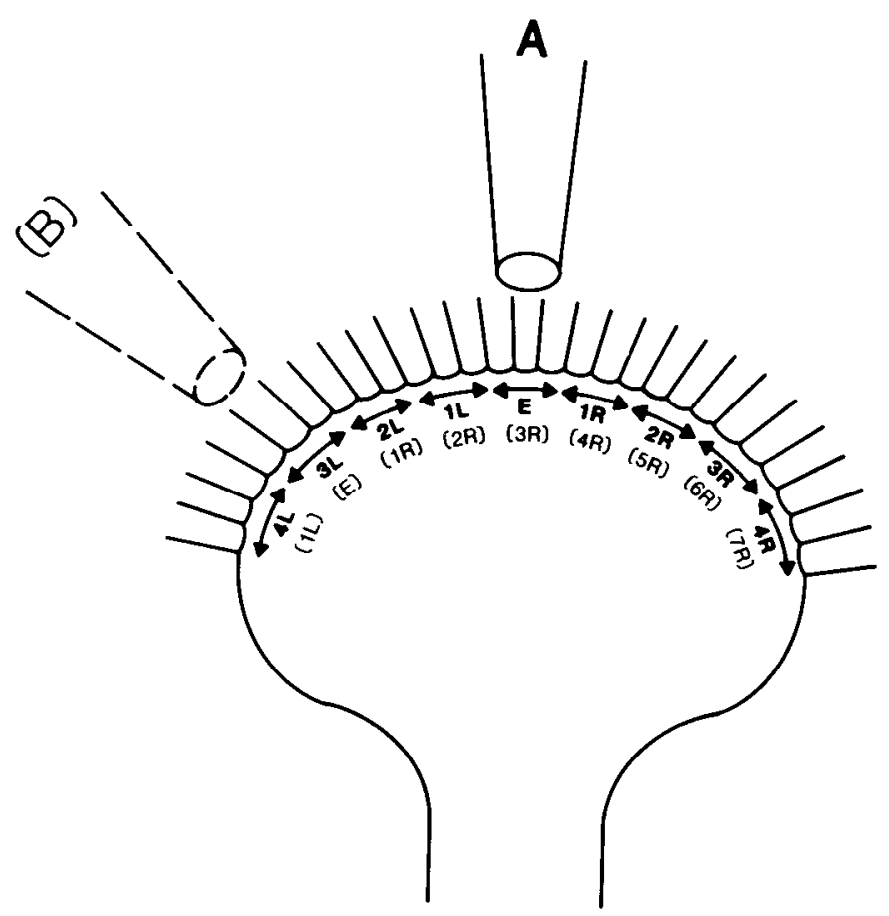

Figure 1. A model growth cone with filopodia, shown with 2 possible placements of a micropipette containing high $\left[\mathrm{Ca}^{2+}\right]$. The scheme of numbering groups of filopodia and interfilopodial spaces by their positions relative to the micropipette is illustrated for positions $A$ and $B$ (numbers bracketed) of the micropipette. See text for details.

Microapplication of $\mathrm{Ca}^{2+} . \mathrm{Ca}^{2+}$ was applied to individual growth cones from glass micropipettes. Three different methods of application were used. One method involved moving a micropipette filled with GCM containing $22 \mathrm{mM} \mathrm{Ca}^{2+}$ (instead of $11 \mathrm{~mm}$ ) and $0.5 \%$ Fast green dye to within a few microns of the growth cone. Brief $(100 \mathrm{msec})$ repetitive $(1 \mathrm{~Hz})$ pulses of gas $\left(\mathrm{O}_{2}\right)$ pressure $(20 \mathrm{psi})$ were applied to the micropipette through the use of a gas valve (9-82-902, General Valve Corp., Fairfield, NJ) connected to an S88 stimulator (Grass Medical Instruments, Quincy, MA). These pulses caused a cloud of ejection solution to form at the orifice (which was $-2 \mu \mathrm{m}$ ) of the clcctrode. A constant rapid perfusion of low- $\mathrm{Ca}^{2+}$ GCM through the chamber was maintained. Fine adjustment of the position of the micropipette, the strength of the applied pressure, and the duration and frequency of the pressure pulses allowed the position of the cloud to be adjusted so that it overlapped only a small portion of the growth cone. But such adjustments were not always successful and sometimes fluid would stop ejecting for several seconds only to restart when the pressure was increased slightly. A second technique involved the use of a micropipette filled with $1 \mathrm{M} \mathrm{CaCl}_{2}$. This electrode had a tip resistance of 4-7 M $\Omega$ and was moved to within 1-2 $\mu \mathrm{m}$ of the growth cone. It was connected to an M701 electrometer amplifier with a bridge circuit (World Precision Instruments, New Haven, CT) that was driven by the S88 stimulator and that fed into a 502A dual-beam oscilloscope (Tektronix, Inc., Beaverton, $\mathrm{OR})$. Brief $(35 \mathrm{msec})$ repetitive $(5 \mathrm{~Hz})$ depolarizing pulses of $0.5-1.5 \mu \mathrm{A}$ were passed through the micropipette to cause ejection of $\mathrm{Ca}^{2+}$. One potential drawback of this technique, which may have contributed to its inconsistent ability to elicit veil formation, is that focal extracellular application of depolarizing pulses to growth cones may inhibit growth (Patel and Poo, 1984). The third, most frequently used, technique was to fill a micropipette with a somewhat larger tip orifice (2-4 M $\Omega$ resistance) with $1 \mathrm{M} \mathrm{CaCl}$, move it to within $1-2 \mu \mathrm{m}$ of the growth cone, and leave it there without applying pulses of pressure or positive current. $\mathrm{Ca}^{2+}, 1000-5000 \times$ more concentrated in the micropipette than the bath, presumably diffused out. No chamber perfusion was used during these applications. Any microapplication experiment in which physical contact was made between the micropipette and the growth cone was discarded. Such contact could be ascertained by immediate local destruction of filopodia and by retention of a discernible contact when the micropipette was withdrawn. 
Table 1. Effects on area of immature veil

\begin{tabular}{|c|c|}
\hline Treatment & $\begin{array}{l}\text { Ratio of areas of } \\
\text { immature veil (After/ } \\
\text { before) }\end{array}$ \\
\hline $1.3 \mathrm{~mm} \mathrm{Ca}^{2+}-4 \mathrm{~mm} \mathrm{EGTA}{ }^{a}$ & $0.00^{b} \quad(1)$ \\
\hline $1.3 \mathrm{mM} \mathrm{Ca}^{2+}-1.4 \mathrm{mM}$ EGTA & $0.00 \quad(1)$ \\
\hline $0.2 \mathrm{mM} \mathrm{Ca}^{2+}$ & $0.43+0.27(8)$ \\
\hline $0.5 \mathrm{mM} \mathrm{Ca}^{2+}$ & $0.36 \pm 0.32(13)$ \\
\hline $1.0 \mathrm{mM} \mathrm{Ca}^{2+}$ & $0.35 \pm 0.43(9)$ \\
\hline $1.3 \mathrm{mM} \mathrm{Ca}^{2+}$ & $0.74 \pm 0.56(4)$ \\
\hline $20.0 \mathrm{mM} \mathrm{Co}^{2+}$ & $0.18 \pm 0.17(5)$ \\
\hline $50.0 \mu \mathrm{M}$ TFP & $0.00 \pm 0.00(5)$ \\
\hline $25.0 \mu \mathrm{M}$ TFP & 0.55 \\
\hline $5.0 \mu \mathrm{M}$ calmidazolium & $0.47 \pm 0.39(5)$ \\
\hline $2.5 \mu \mathrm{M}$ calmidazolium & 0.72 \\
\hline $1.0 \mu \mathrm{M}$ calmidazolium & 0.94 \\
\hline $20.0 \mathrm{mM} \mathrm{Ba}^{2+, c}$ & $4.16 \pm 2.20^{d}(4)$ \\
\hline $5.0 \mu \mathrm{M} \mathrm{A} 23187$ & $6.68 \pm 3.00$ \\
\hline
\end{tabular}

${ }^{2}$ In this first group, perfusion with normal culture medium (containing $11 \mathrm{mM}$ $\mathrm{Ca}^{2+}$ ) was followed by perfusion with normal culture medium modified only as indicated.

${ }^{\mathrm{b}}$ In this first group, veil area was measured 13-17 min after the start of perfusion with the altered culture medium. Veil area often continued to decrease after this time. Values are means \pm SD for the number of experiments given in parentheses. ' In this second group, perfusion with reduced $\mathrm{Ca}^{2+}(0-0.5 \mathrm{~mm})$ culture medium (to eliminate immature veils) was followed by perfusion with the same culture medium to which the indicated chemical was added.

${ }^{d}$ In this second group, the area of immature veil was measured at its largest (usually within $10 \mathrm{~min}$ ) during perfusion with the altered reduced $\mathrm{Ca}^{2+}$ medium and compared with the area just before starting perfusion with that medium. Values are means $\pm S D$ for the number of experiments given in parentheses.

Computer processing. For the experiment depicted in Figure 5, the puffs of solution (colored by Fast green dye) emitted from the micropipette are clearly visible on the videotape record. However, because they were brief $(100 \mathrm{msec})$ and quickly swept away by a rapid bath perfusion, thcy cannot bc seen in single still frames. Thus, the image was digitally processed to allow visualization of the puff in a photograph. A PC's Limited $28608 \mathrm{~L}$ microcomputer with 40 megabyte hard disk (Dell Computer, Austin, TX) and DT 2851 high-resolution frame grabber and DT 2858 auxiliary frame processor (Data Translation, Marlboro, MA) was used. Two frames were captured and stored, one during a puff and one after that puff but before the next. The first frame was subtracted from the second, yielding a frame showing the puff in white. All pixel values were then multiplied by 15 to boost the signal and run through a lookup table to perform a complement transformation so the puff would appear black rather than white.

Analysis of data. The size of the immature veil area of a growth cone was measured by outlining the area on a transparency taped on the screen of the TV monitor. That region at the distal margins of the growth cone which was flat and had few membranous organclles was defined as immature veil. The outlined areas were cut out and weighed.

In the experiments involving focal application of $\mathrm{Ca}^{2+}$, the size of the growth cone and the position of the micropipette varied from one experiment to the next. Sometimes the micropipette would be at the left or right extreme of the distal margin of the growth cone; at other times, somewhere in between. Therefore, the number of growth cone filopodia, and thus the number of possible paths for veil extension, on either side of the micropipette, varied. Those interfilopodial spaces directly overlain by the micropipette were grouped together as the $\mathrm{E}$ bin. Since there were most often 3 spaces in this bin, the spaces ranging out from either side of the $E$ bin were grouped in threes. Thus, the first 3 spaces to the left of the E bin formed the Ll bin, the next 3 the L2 bin, and so on. If the micropipette were at position $A$ in the diagram in Figure 1 , there would bc $4 \mathrm{~L}$ bins and $4 \mathrm{R}$ bins. If it were instead at position $\mathrm{B}$, there would be $1 \mathrm{~L}$ bin and $7 \mathrm{R}$ bins. A narrower growth cone would have fewer total bins. Thus, there was an $\mathrm{E}$ bin in all 13 experiments, $L 1$ and $R 1$ bins in most of them, but $L 7$ and $R 7$ bins in only a few. Each probability plotted in Figure 7 is simply the number of experiments in which the bin was the site of formation of the first, or only, veil that formed divided by the number of experiments in which that bin was present. The position of the micropipette was shifted from one experiment to the next so that, in case there was a position on the growth cone that was intrinsically preferable for veil formation, the micropipette was not always placed at it.

Chemicals. Tetrodotoxin (TTX), compound R24571 (calmidazolium), calcium ionophore A23187, and EGTA were all obtained from Sigma (St. Louis, MO). Stock solutions in DMSO of calmidazolium and $\mathrm{A} 23187$, at 2.5 and $10 \mathrm{~mm}$, respectively, were stored at $4^{\circ} \mathrm{C}$. Trifluoperazine (TFP) dihydrochloride was a gift from Smith Kline \& French Research Laboratories (Philadelphia, PA).

\section{Results}

Growth cones of Aplysia buccal neurons in culture with large, well-defined veil regions were selected for study. VEC-DIC microscopy was used to observe the growth cones, allowing the visualization of small intracellular membranous organelles such as vesicles as well as larger organelles such as mitochondria. As previously observed (Goldberg and Burmeister, 1986), the distal veil region was flat and had relatively few organelles, while the central, more proximal region was thicker and full of organelles moving randomly (Fig. 2a).

\section{Disappearance of immature veil}

Reducing $\left[\mathrm{Ca}^{2+}\right]$ in the bathing solution from its normal value of 11 to $1.3 \mathrm{~mm}$ or lower usually caused a large reduction, sometimes a complete disappearance, of the area of immature veil in the growth cone (Table 1). Growth of the neurite stopped as a result, since growth occurs by formation and then maturation of veils (Goldberg and Burmeister, 1986). Perfusion with culture medium containing either $1.3 \mathrm{mM} \mathrm{Ca}^{2+}-4$ mM EGTA (which should result in a final $\left[\mathrm{Ca}^{2+}\right]_{\circ}$ of approximately $0.3 \mu \mathrm{M}$ ) or $1.3 \mathrm{mM} \mathrm{Ca}^{2+}-1.4 \mathrm{~mm}$ EGTA (which should result in a final $\left[\mathrm{Ca}^{2+}\right]_{0}$ of approximately $10 \mu \mathrm{M}$ ) caused complete disappearance of immature veil within $5 \mathrm{~min}$. Lesser reductions in $\left[\mathrm{Ca}^{2+}\right]_{\mathrm{o}}$, achieved without the use of EGTA, usually caused most of the immature veil to disappear (Table 1). More than two-thirds of the experiments done at each of the $\left[\mathrm{Ca}^{2+}\right]_{0}$ of $0.2,0.5$, and 1.0 $\mathrm{mm}$ resulted in the eventual disappearance of more than $80 \%$ of the area of immature veil. In many instances, the majority at $0.2 \mathrm{mM}$, the disappearance was complete. The disappearance was usually slower than when EGTA was used, but by approximately $15 \mathrm{~min}$ after beginning perfusion with the low $\left[\mathrm{Ca}^{2+}\right]$ solution, the mean reduction in area of immature veil at each of the 3 concentrations was $55-65 \%$. Four experiments were done with the $\left[\mathrm{Ca}^{2+}\right]_{0}$ set at $1.3 \mathrm{~mm}$ (the concentration in unmodified L-15 medium); 2 resulted in large reductions in the area of immature veil, 2 did not.

Immature veil could theoretically disappear in 2 ways. There could be retraction of the distal margin or there could be continued maturation in a proximodistal direction in the absence of further advancement of the distal margin. Both were found to occur, often in the same experiment. An example of disappearance by retraction is shown in Figure 2, $a, b$. Here there was some veil formation that occurred shortly after switching to bathing medium containing $0.5 \mathrm{~mm} \mathrm{Ca}{ }^{2+}$, since inhibition of veil formation was not always immediate, but most of the large area of immature veil has disappeared after $13 \mathrm{~min}$. Typically, the retraction of the distal margin proceeded just up to maturing areas, that is, areas in which significant numbers of vesicles could be detected. An example of disappearance by maturation is shown in Figure 2, $c, d$. Here there was no advancement of the distal margin, that is, no new veil projected 

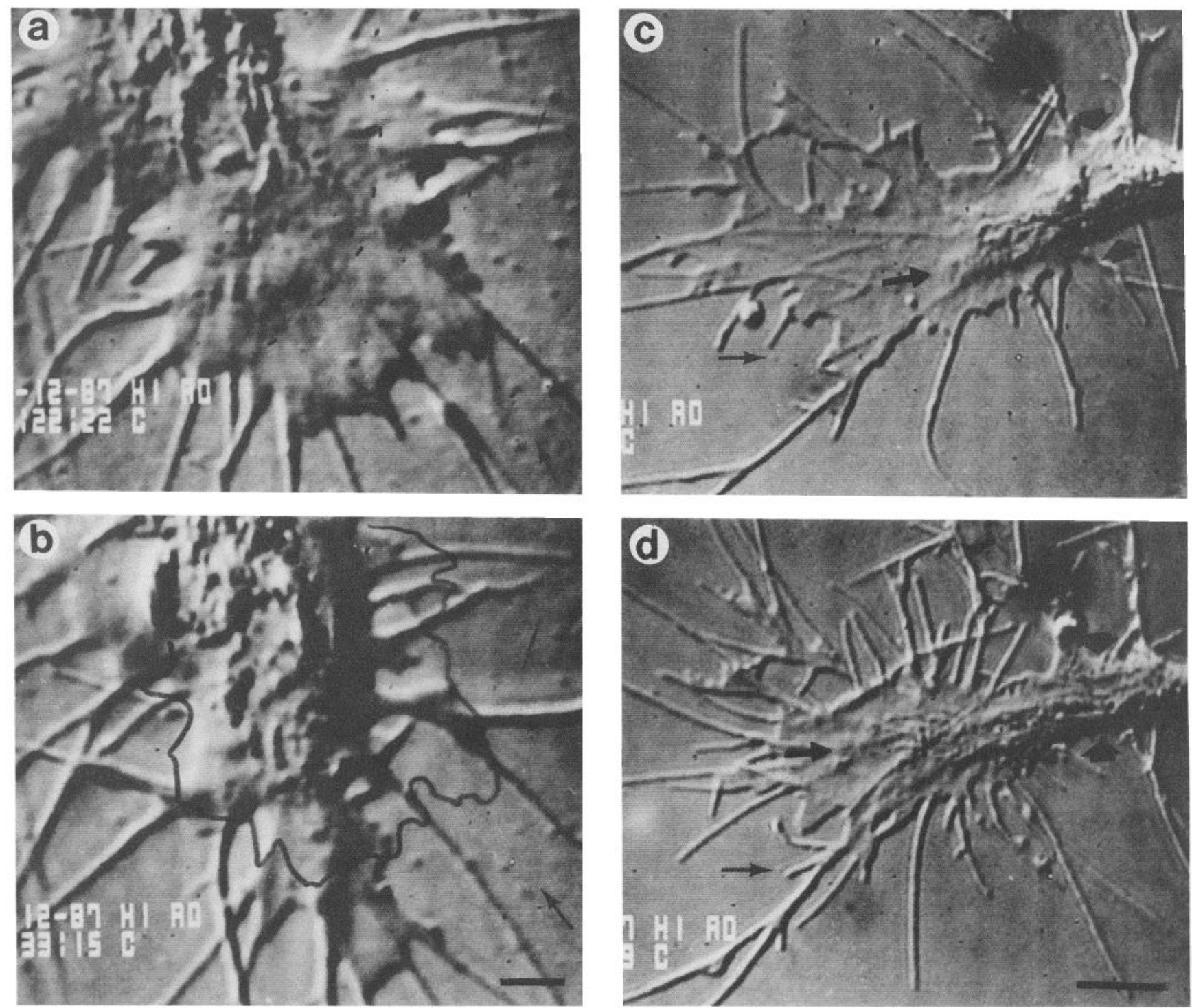

Figure 2. Reduction of area of immature veil in response to reduced $\left[\mathrm{Ca}^{2+}\right]_{0}$. Panels $a$ and $b$ show reduction by retraction. $a, 2$ min after starting perfusion with medium containing $0.5 \mathrm{mM} \mathrm{Ca}^{2+}$, before veil reduction has started. Dashed line marks boundary between mature and maturing veil. $b, 13 \mathrm{~min}$ after starting perfusion. Perimeter of growth cone as it was in $a$ is outlined to show reduction. Note that the retraction of the veil goes back just to the maturing area demarcated by the dashed line in a. Arrow points to diamond-shaped cluster of 4 particles on substrate that can be used as landmarks. Scale bar, $2 \mu \mathrm{m}$. Panels $c$ and $d$ show reduction by maturation. $c$, Just before starting perfusion with medium containing $0.2 \mathrm{mM} \mathrm{Ca}^{2+} . d, 13 \mathrm{~min}$ after starting perfusion. Note the advance of the swollen, vesicle-filled region (arrow) and the thinning proximally into mature axon (arrowhead). Thin arrow points to particle on substrate that can be used as landmark. Scale bar, $5 \mu \mathrm{m}$.

out, while maturation of the already present veil by invasion of vesicles from the central region of the growth cone and swelling continued. Thinning of the central region into axon can also be seen to have proceeded. Twenty-two experiments performed with $\left[\mathrm{Ca}^{2+}\right]_{\text {。 }}$ of $0.2,0.5,1.0$, or $1.3 \mathrm{~mm}$ could be analyzed to determine the mode of disappearence of immature veil (Table 1). In 9 the disappearance was entirely by retraction of the distal margin, in 3 it was entirely by continued maturation in the absence of advancement of the distal margin, and in 10 both retraction and continued maturation contributed.

As can be seen in Figure 2, existing filopodia were unaffected by solutions of reduced $\left[\mathrm{Ca}^{2+}\right]_{\mathrm{o}}$ that caused complete disappearance of immature veil. In fact, when the disappearance was by retraction of the distal margin, lengths of filopodia that had been overlain by veil were unmasked. Also, no obvious differ- ence was ever detected in velocity or amount of membranous organelles moving by bidirectional fast axonal transport, though no quantitation was done.

Immature veil could be made to disappear in the presence of the normal $\left[\mathrm{Ca}^{2+}\right]_{\circ}$ of $11 \mathrm{~mm}$ if adequate amounts of $\mathrm{Co}^{2+}$ or either of 2 drugs that inhibit certain $\mathrm{Ca}^{2+}$-dependent enzymes was added to the bathing medium (Table 1). Perfusion with normal culture medium containing $20 \mathrm{mM} \mathrm{Co}^{2+}$, which greatly reduces influx through $\mathrm{Ca}^{2+}$ membrane channels in Aplysia neurons (Shapiro et al., 1980), as in neurons of other species, greatly reduced the area of immature veil within minutes (Table 1). As in the experiments with reduced $\left[\mathrm{Ca}^{2+}\right]_{0}$, this was found to occur both by retraction and by maturation (Fig. 3). Concentrations of trifluoperazine (TFP) in normal culture medium of 25 or 50 $\mu \mathrm{M}$ greatly reduced the area of immature veil, as did $5 \mu \mathrm{M}$ cal- 

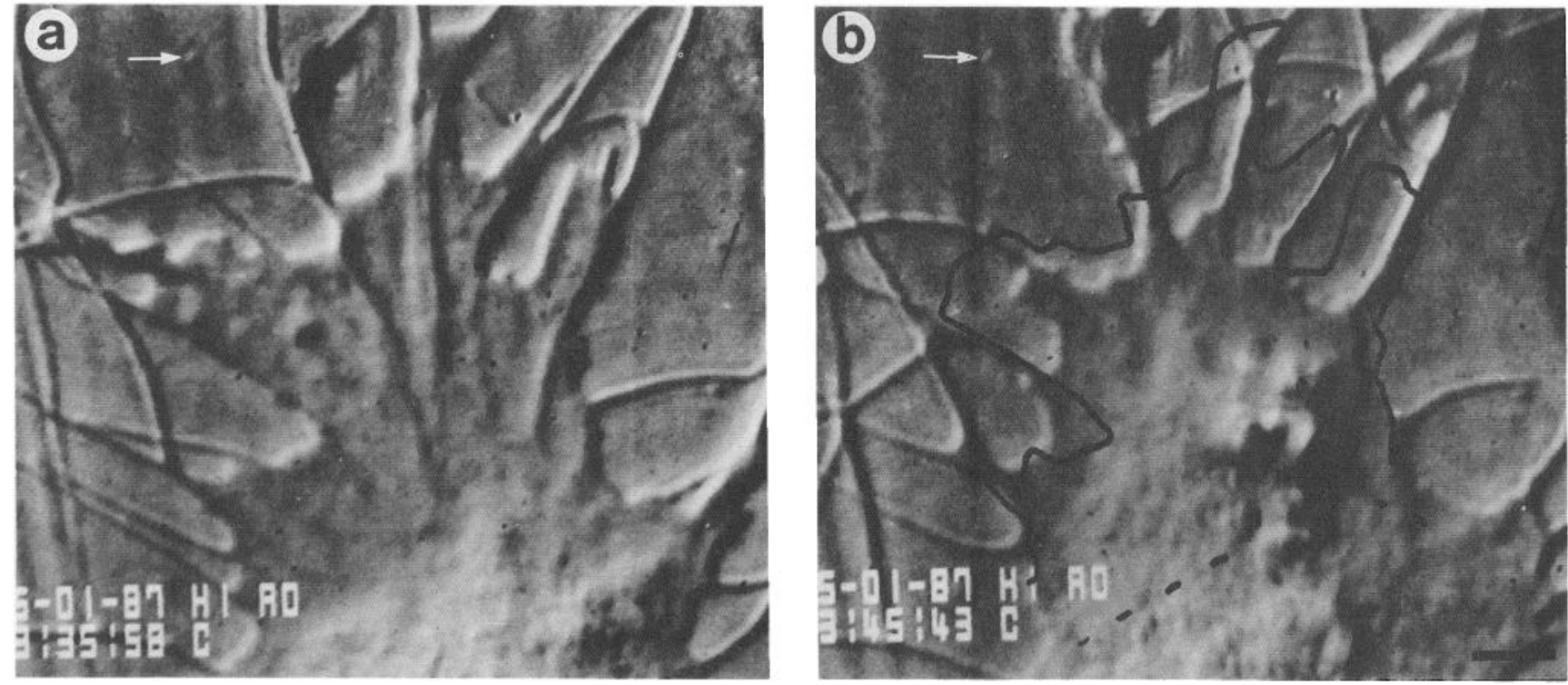

Figure 3. Reduction of area of immature veil by retraction and maturation in response to $\mathrm{Co}^{2+}$. $a$, Just before starting perfusion with medium containing $11 \mathrm{~mm} \mathrm{Ca}{ }^{2+}$ and $20 \mathrm{mM} \mathrm{Co}^{2+}$. b, 9 min after starting perfusion. Solid line is outline of perimeter of veil, and dashed line demarcates border between immature and maturing veil as they were in a. Arrow points to particle on substrate that may be used as landmark. Scale bar, $2 \mu \mathrm{m}$.

midazolium (R24571) (Table 1). Calmidazolium, $2.5 \mu \mathrm{M}$, had a markedly milder effect and $1 \mu \mathrm{M}$ calmidazolium no effect at all during 51 min of perfusion. Reformation of veils was usually seen when normal culture medium was reintroduced, though an overly long exposure to $\mathrm{Co}^{2+}$ did not allow this.

\section{Reformation of veils}

The disappearance of immature veil caused by reduced $\left[\mathrm{Ca}^{2+}\right]_{\text {。 }}$ was reversed by restoration of the normal $\left[\mathrm{Ca}^{2+}\right]_{0} . \mathrm{Ba}^{2+}$, which flows well through $\mathrm{Ca}^{2+}$ membrane channels in neurons of $\mathrm{Aply}$ sia (Shapiro et al., 1980), as of other species, could substitute for $\mathrm{Ca}^{2+}$ in causing reformation of veils. When $20 \mathrm{mM} \mathrm{Ba}^{2+}$ was added to culture medium containing $0.2 \mathrm{mM} \mathrm{Ca}^{2+}$, which had caused the disappearance of immature veil, new veils began forming within a minute, and a very large area of immature veil was present after 3 min (Fig. 4). Washing out the $\mathrm{Ba}^{2+}$ caused the veils to disappear and then readdition of $20 \mathrm{mM} \mathrm{Ba}^{2+}$ again caused extensive veil formation within a few minutes. In some Aplysia neurons $\mathrm{Ba}^{2+}$ can cause depolarization and repetitive firing of action potentials. If it were having that effect on the buccal neurons used in these experiments there might have been substantial influx of $\mathrm{Ca}^{2+}$ despite the relatively low $\left[\mathrm{Ca}^{2+}\right]_{0}$ (see following paragraph on A23187). To lessen this possibility, experiments were done in which the cultured neurons were exposed to a bathing solution that contained no added $\mathrm{Ca}^{2+}$ at all and $30 \mu \mathrm{M}$ TTX, which completely suppresses current through the $\mathrm{Na}^{+}$channel and thus would reduce the depolarization and, in some cells, prevent the firing of action potentials. Veils disappeared, as expected. Addition of $20 \mathrm{mM} \mathrm{Ba}^{2+}$ to this solution caused veils to reform (Table 1 ).

The results of the experiments with $\mathrm{Co}^{2+}$ and $\mathrm{Ba}^{2+}$ suggest that reducing $\left[\mathrm{Ca}^{2+}\right]_{0}$ caused the disappearance of veils by reducing entry of $\mathrm{Ca}^{2+}$ into the neuron through $\mathrm{Ca}^{2+}$ channels in the plasma membrane. Experiments were done to substantiate this possibility. Neurons were exposed to GCM containing 0.5 $\mathrm{mM} \mathrm{Ca}^{2+}$, which caused disappearance of veils. A23187, a Ca ${ }^{2+}$ ionophore, was then added at $5 \mu \mathrm{M}$ to the bathing medium. Within a few minutes, veils could be seen to form (Table 1). Usually, the amount of veil area reformed was less than that lost and the veils did not persist beyond about $10 \mathrm{~min}$.

Experiments were done to assess the proximity of the site of action of $\mathrm{Ca}^{2+}$ to the site of veil formation. These could be done because veils did not form after a time in low $\left[\mathrm{Ca}^{2+}\right]$ bathing medium but formed rapidly after restoring $\left[\mathrm{Ca}^{2+}\right]_{0}$ to normal. The idea of these experiments was to restore $\left[\mathrm{Ca}^{2+}\right]_{\mathrm{o}}$ sufficiently at only a small region of the growth cone. To do this, $\mathrm{Ca}^{2+}$ was microapplied to the growth cone through glass micropipettes with tip diameters similar in size to the distance between 2 adjacent filopodia. Sometimes ( $21 \%$ of the growth cones) no veils formed anywhere on the growth cone in response to this microapplication. Presumably this was because $\left[\mathrm{Ca}^{2+}\right]_{\text {o was not }}$ brought to the appropriate level. Usually, however, a veil formed within a few minutes of microapplication of $\mathrm{Ca}^{2+}$, occasionally followed by additional veils. One example is given in Figure 5, which shows pulses of GCM containing $22 \mathrm{mM} \mathrm{Ca}^{2+}$ applied through the application of gas pressure to the micropipette. This solution, colored with Fast green dye, was applied to only a small part of the growth cone, with a steady bath perfusion sweeping it away before it could spread over the entire growth cone. Within 2 min a single veil extended next to the micropipette. This technique of microapplication was difficult to control, so more often $\mathrm{Ca}^{2+}$ was ejected from a $1 \mathrm{M} \mathrm{CaCl}_{2}$ micropipette solution by the application of brief pulses of positive current.

Another method of microapplication, which was used most often, was simply to allow a micropipette containing $1 \mathrm{M} \mathrm{CaCl}_{2}$ to remain next to the growth cone without a steady bath perfusion. The presumed diffusion of $\mathrm{Ca}^{2+}$ from the electrode often caused veil formation (Fig. 6). Microapplication by 1 of the 3 techniques elicited veil formation within a few minutes in 13 different growth cones. The probability of formation of the first, or only, veil at various positions on the periphery of the growth 

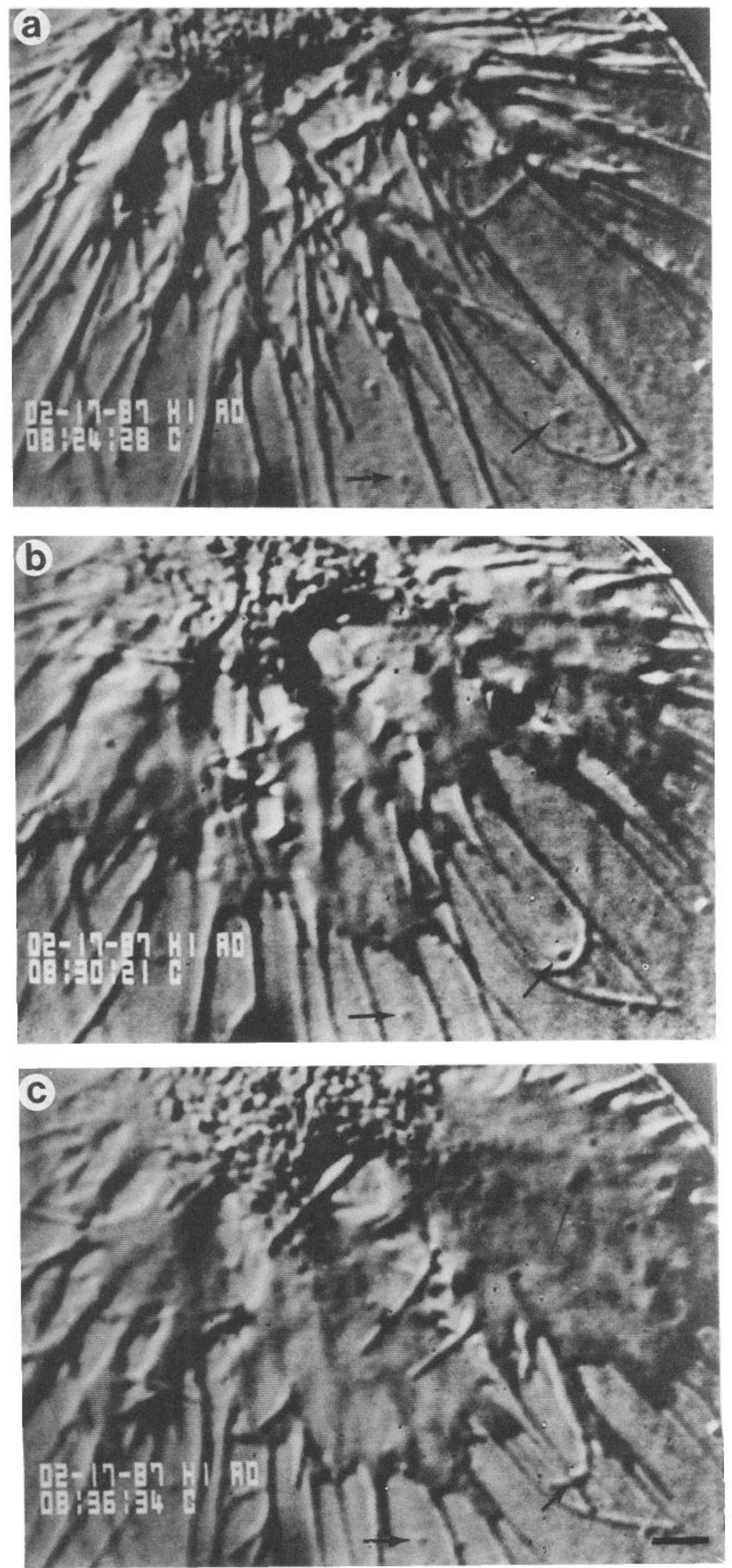

Figure 4. Reformation of veils in low $\left[\mathrm{Ca}^{2+}\right]_{0}$ in response to $\mathrm{Ba}^{2+}, a, 7 \mathrm{~min}$ after starting perfusion with medium containing $0.2 \mathrm{mM} \mathrm{Ca}^{2+}$ a large area of immature veil has almost entirely disappeared. $b, 3.5 \mathrm{~min}$ after starting perfusion with medium containing $0.2 \mathrm{~mm}$ $\mathrm{Ca}^{2+}, 20 \mathrm{~mm} \mathrm{Ba}^{2+}$ there is already reappearance of much veil. $c, 11 \mathrm{~min}$ after starting perfusion with medium containing $\mathrm{Ba}^{2+}$ huge areas of veil have formed. Arrows point to particles on the substrate that may be used as landmarks. Scale bar, $2 \mu \mathrm{m}$. 

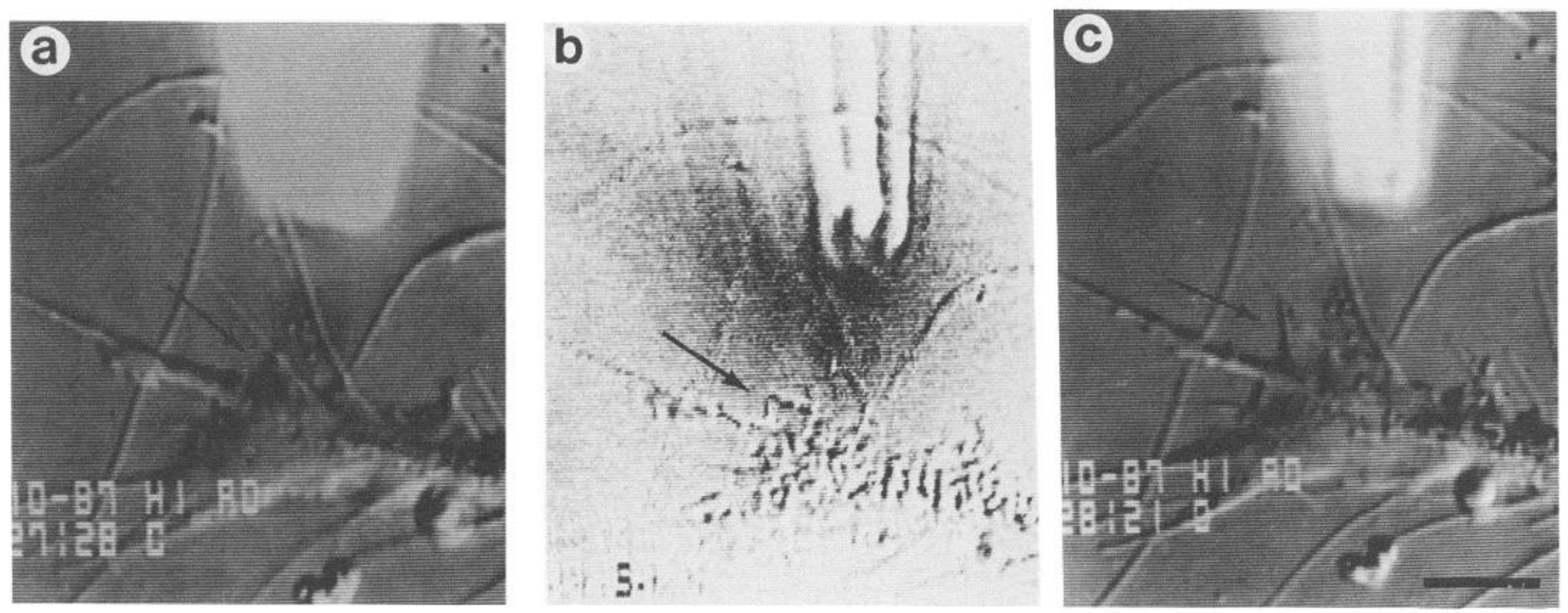

Figure 5. Formation of veil near a micropipette from which $\mathrm{Ca}^{2+}$ is being ejected, in bathing medium containing $0.5 \mathrm{~mm} \mathrm{Ca}{ }^{2+} \cdot a$, Micropipette containing culture medium with $22 \mathrm{~mm} \mathrm{Ca}^{2+}$ and $0.5 \%$ Fast green dye has just been moved next to a growth cone that has lost its veils by being exposed to bathing medium containing $0.5 \mathrm{mM} \mathrm{Ca}^{2+}$. The arrow points to the site where the veil will form when ejection of solution from the micropipette begins. $b$, Image of the growth cone and micropipette that has been digitally processed to make the puff of solution released from the micropipette clearly visible in the still photograph. The puff is beginning to be swept away by a rapid bath perfusion, as evidenced by the tail pointing to the upper left. Because this image was obtained by frame subtraction (see Materials and Methods for details of image processing), much detail of the growth cone has been lost, but it is possible to see a new projection from the perimeter (arrow), which is a growing veil. $c$, 31 sec later the veil is fully formed (arrow). Veils have formed nowhere else on the perimeter of the growth cone. Scale bar, $5 \mu \mathrm{m}$.

cone relative to the position of the micropipette (the latter varied from one growth cone to the next-see Materials and Methods) is plotted in Figure 7. This graph clearly indicates that the position of the micropipette strongly influenced the site of veil formation; veils usually first formed near the micropipette.

\section{Discussion}

The results reported here confirm previous findings that veil formation is $\mathrm{a} \mathrm{Ca}^{2+}$-dependent process (Letourneau, 1975a, 1979; Anglister et al., 1982), support the idea that the important site of action for $\mathrm{Ca}^{2+}$ is intracellular (Anglister et al., 1982) rather than extracellular (Letourneau, 1975a, 1979), and demonstrate that the $\mathrm{Ca}^{2+}$-dependent step occurs very close to the site of veil formation. They also suggest that the subsequent sequence of morphological transformation of the veil (Goldberg and Burmeister, 1986) may be substantially less sensitive to $\left[\mathrm{Ca}^{2+}\right]_{i}$.

\section{$\mathrm{Ca}^{2+}$-dependence of veil formation}

It seems likely that it is a large reduction in the normal flux of $\mathrm{Ca}^{2+}$ into Aplysia buccal neurons in vitro that causes the disappearance of immature veils (veils that are flat and have relatively few membranous organelles) in their growth cones. It might instead be that $\mathrm{Ca}^{2+}$ acts at an extracellular site to regulate the amount of veil. Binding of some neurons to certain factors associated with the substrate is $\mathrm{Ca}^{2+}$-dependent (Bixby et al., 1987), and it was suggested that the formation of veils by the growth cones of chick sensory neurons induced by elevating $\left[\mathrm{Ca}^{2+}\right]_{\mathrm{o}}$ to a supranormal level was the result of a $\mathrm{Ca}^{2+}$-promoted increase in adhesivity of the substrate (Letourneau, 1975a, 1979). On the other hand, veil formation in neuroblastoma cells was promoted by enhanced $\mathrm{Ca}^{2+}$ influx (Anglister et al., 1982). In experiments reported here, $\mathrm{Co}^{2+}$, which blocks $\mathrm{Ca}^{2+}$ channels, caused veil disappearance even in the presence of normal $\left[\mathrm{Ca}^{2+}\right]_{\text {. }}$.
$\mathrm{Ba}^{2+}$, which flows well through $\mathrm{Ca}^{2+}$ channels and supports at least certain types of neurotransmitter release (Silinsky, 1978; Nakazato and Onoda, 1980), caused extensive veil formation even in the nominal absence of extracellular $\mathrm{Ca}^{2+}$. Still, both of these ions might act at an extracellular site, inhibiting or substituting for $\mathrm{Ca}^{2+}$. The stimulation of veil formation in low $\left[\mathrm{Ca}^{2+}\right]_{\text {o }}$ by $\mathrm{A} 23187$, an organic compound that promotes the flux of $\mathrm{Ca}^{2+}$ across the plasma membrane, cannot, however, be readily explained by an extracellular site of action for $\mathrm{Ca}^{2+}$, and so the experiments viewed as a whole favor the importance of sustained $\mathrm{Ca}^{2+}$ influx. Most likely it is the contribution of this influx to $\left[\mathrm{Ca}^{2+}\right]_{i}$, rather than the current itself, that is important because some neurons, embryonic frog spinal (Bixby and Spitzer, 1984) and chick sensory (Letourneau and Wessells, 1974), for example, grow well in $\mathrm{Ca}^{2+}$-free culture medium. These Aplysia neurons, as well as certain other cultured neurons (Suarez-Isla et al., 1984), probably need a substantial influx of $\mathrm{Ca}^{2+}$ to maintain $\left[\mathrm{Ca}^{2+}\right]_{i}$ at the level needed for formation of veils. In fact, certain Aplysia neurons have a substantial $\mathrm{Ca}^{2+}$ current at the resting potential (Shapiro et al., 1980).

While it is likely that intracellular $\mathrm{Ca}^{2+}$ plays a role in veil formation and maintenance, the data reported here do not permit a conclusion about whether changes in $\left[\mathrm{Ca}^{2+}\right]_{\mathrm{i}}$ normally control those processes. It may be that $\left[\mathrm{Ca}^{2+}\right]_{i}$ in the growth cone is maintained at a level sufficient to permit veil formation, which is actually triggered by changes in another factor. Changes in $\left[\mathrm{Ca}^{2+}\right]_{i}$ might occasionally regulate the area of immature veil. For example, the retraction of growth cones of embryonic neurons of chick retina and sympathetic ganglion when they contact heterotypic neurites in vitro (Kapfhammer and Raper, 1987) might be caused by a precipitous drop in $\left[\mathrm{Ca}^{2+}\right]_{\mathrm{i}}$, though the effect on growth cone structure, with retraction of filopodia and central region of the growth cone, is more extreme than seen in 

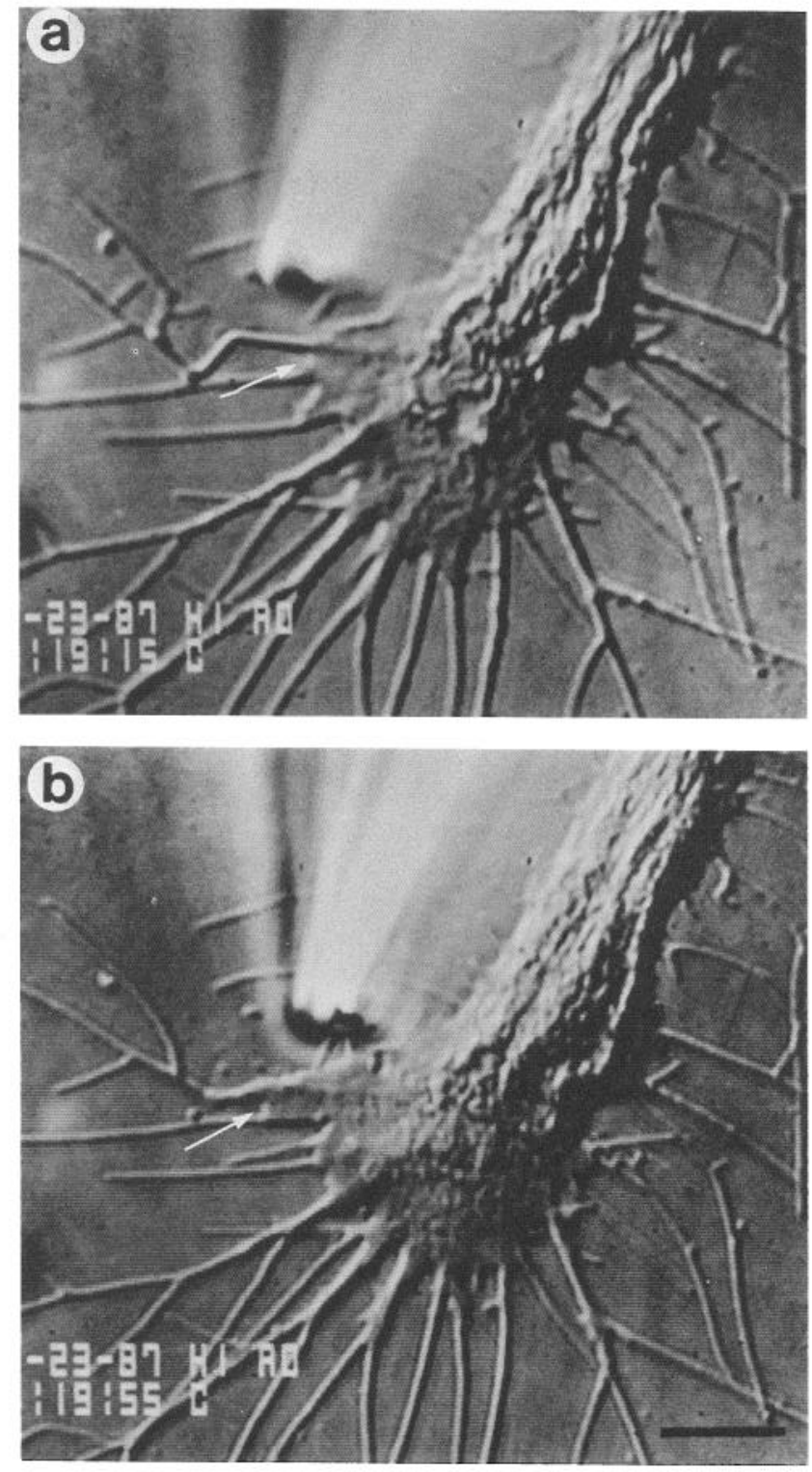

Figure 6. Formation of veil next to a micropipette containing $1 \mathrm{~m}$ $\mathrm{CaCl}$, in bathing medium containing $0.5 \mathrm{mM} \mathrm{Ca}^{2+} . a$, The micropipette has just (within the preceding $10 \mathrm{sec}$ ) been moved next to a growth cone that lost its veils by being exposed to bathing medium containing 0.5 $\mathrm{mM} \mathrm{Ca}{ }^{2+}$, and a veil is just beginning to grow. $b, 40 \mathrm{sec}$ later the veil has reached its full extent. No other veils have formed. Neither depolarization nor pressure was applied to the micropipette, $\mathrm{Ca}^{2+}$ presumably escaping by diffusion. Scale bar, $5 \mu \mathrm{m}$.

the present experiments. Alternatively, veil formation might always be triggered directly by a change in $\left[\mathrm{Ca}^{2+}\right]_{\mathrm{i}}$, much like synaptic release.

Intracellular $\mathrm{Ca}^{2+}$ may act in veil formation and maintenance by binding to calmodulin. Concentrations of TFP that profoundly inhibit $\mathrm{Ca}^{2+} /$ calmodulin-dependent protein phosphorylation in homogenates of Aplysia ganglia (DeRiemer et al., 1984) greatly decreased the area of immature veil. But these concentrations inhibit $\mathrm{Ca}^{2+} /$ phospholipid-dependent protein phosphorylation equally well (DeRiemer et al., 1985). However, $5 \mu \mathrm{M}$ calmidazolium, which almost completely inhibits $\mathrm{Ca}^{2+} / \mathrm{cal}-$ modulin-dependent phosphorylation in Aplysia homogenates (DeRiemer et al., 1984) while scarcely affecting protein kinase

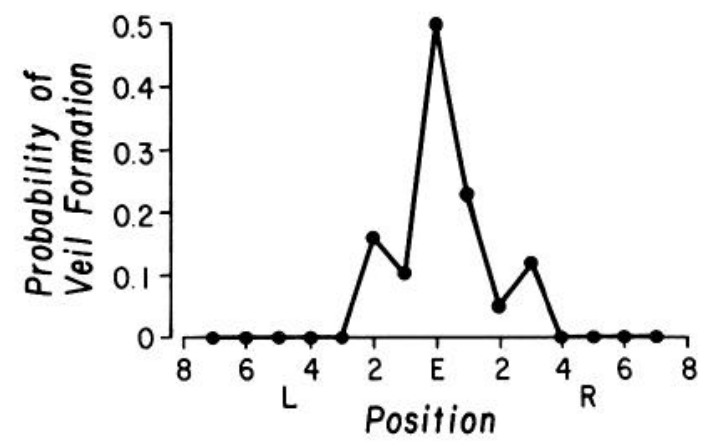

Figure 7. Veils preferentially form near a micropipette source of $\mathrm{Ca}^{2+}$ in low- $\mathrm{Ca}^{2+}$ bathing medium. Graph shows the probability, when the micropipette is moved next to the growth cone, of formation of the first, usually only, veil as a function of distance of the site of formation from the micropipette. $E$ is the site of the micropipette and 1-8 are increasingly distant sites on either side of it. Had the veils formed at random locations, a large, well-defined peak anywhere would have been very unlikely. See Materials and Methods for details of experiments and analysis of data.

C (DeRiemer et al., 1985), also caused immature veils to disappear. $2.5 \mu \mathrm{M}$ calmidazolium, which partially inhibits $\mathrm{Ca}^{2+}$ / calmodulin-dependent protein phosphorylation, had a milder, though noticeable effect, on veil area, while $1 \mu \mathrm{M}$ calmidazolium affects neither. The role of $\mathrm{Ca}^{2+}$ in veil formation and maintenance need not be mediated by a protein kinase, as there are other types of enzymes activated by calmodulin. Nor do the present results prove that calmodulin is involved, for amphipathic molecules like TFP and calmidazolium may interact directly with the lipid bilayer to produce changes in shape (Sheetz and Singer, 1974; but, in contrast, see Conrad and Singer, 1981). However, such an involvement of calmodulin would not be surprising in light of its presumed involvement in many cellular processes including, perhaps, exocytosis (Knight and Baker, 1982).

Although it is clear that reducing $\mathrm{Ca}^{2+}$ influx inhibits formation of veils and that restoring the influx elicits new formation, why should reduced $\mathrm{Ca}^{2+}$ influx cause retraction of immature veil, as occurred in most of the cases analyzed? An attractive possibility is that the $\mathrm{Ca}^{2+}$-dependent step in veil formation is the insertion of new membrane by exocytosis, as has been suggested (Anglister et al., 1982). There is abundant endocytosis at growth cones (Wessells et al., 1974; Bunge, 1977; Cheng and Reese, 1987), so the amount of immature veil may be determined by the balance between exocytosis and endocytosis. If only the former were $\mathrm{Ca}^{2+}$-dependent (von Grafenstein et al., 1986), reduction of $\mathrm{Ca}^{2+}$ influx would cause retraction of immature veil.

\section{Insensitivity of veil maturation to reduced $\mathrm{Ca}^{2+}$ influx}

In more than half of the experiments analyzed, the maturation that morphologically transforms newly formed veils first into the central, organelle-rich region of the growth cone and then into axon (Goldberg and Burmeister, 1986) continued while formation of new veil was inhibited by low $\left[\mathrm{Ca}^{2+}\right]_{0}$, contributing to the disappearance of immature veil. One explanation is that maturation is relatively independent of $\mathrm{Ca}^{2+}$. The early stages of maturation involve a separation of the closely apposed plasma membranes that bound the veil top and bottom and an ingress of vesicles from the central region of the growth cone (Goldberg and Burmeister, 1986). Most vesicles enter by what 
appears to be Brownian motion, with some entering by fast axonal transport. Neither of these types of organelle movement requires $\mathrm{Ca}^{2+}$ (Adams, 1982). In addition, maturation seems to stabilize the veil, in that retraction of veil caused by reducing $\mathrm{Ca}^{2+}$ influx usually proceeded only up to the border between immature veil and maturing veil.

\section{Veil forms at the site of the $\mathrm{Ca}^{2+}$-dependent step}

The results of the microapplication experiments indicate that the site of the $\mathrm{Ca}^{2+}$-dependent step is close to the site of veil formation, for presumably it was near the micropipette first, or only, that $\left[\mathrm{Ca}^{2+}\right]_{0}$ would be sufficient for veil formation, and it was usually near the micropipette that the first, or only, veil formed. We have previously suggested that veil formation is caused either by a rearrangement of the submembranous meshwork of microfilaments which permits the veil to project forward or simply by an expansion of the membrane surface area due to addition of new membrane by exocytosis. Regarding the first mechanism, it is reasonable to expect an involvement of $\mathrm{Ca}^{2+}$ in the cytoskeletal rearrangement, since the activities of several proteins that control the organization of actin in the cytoplasm are regulated by $\mathrm{Ca}^{2+}$ (Weeds, 1982). Also, this mechanism requires that the site of cytoskeletal rearrangement be the site of veil formation. As for the second mechanism, one would expect exocytosis to be $\mathrm{Ca}^{2+}$-dependent, but it is not known where in the growth cone membrane is added. The results here indicate that if it is net addition of membrane that triggers veil formation, the veil forms where the membrane is added. This would agree with results reported recently by Chong and Rccsc (1987), who found disks of membrane that may be the intracellular agents of exocytotic addition of membrane to the surface to be located near the base of filopodia, which is where veils form. Observation of addition of membrane to the surface of living growth cones by video-intensified fluorescence microscopy should allow direct assessment of this possibility. Also, if it is a change in $\left[\mathrm{Ca}^{2+}\right]_{0}$ that directly triggers veil formation, then the site of formation, which will strongly influence the direction of axon growth, is probably determined by focal changes in $\left[\mathrm{Ca}^{2+}\right]_{\mathrm{i}}$ within the growth cone.

\section{References}

Adams, R. J. (1982) Organelle movement in axons depends on ATP. Nature 297: 327-329.

Allen, R. D. (1985) New observations on cell architecture and dynamics by video-enhanced contrast optical microscopy. Annu. Rev. Biophys. Chem. 14: 265-290.

Anglister, L., I. C. Farber, A. Shahar, and A. Grinvald (1982) Localization of voltage-sensitive calcium channels along developing neurites: Their possible role in regulating neurite elongation. Dev. Biol. 94: 351-365.

Bamburg, J. R., D. Bray, and K. Chapman (1986) Assembly of microtubules at the tip of growing axons. Nature 321: 788-790.

Bixby, J. L., and N. C. Spitzer (1984) Early differentiation of vertebrate spinal neurons in the absence of voltage-dependent $\mathrm{Ca}^{2+}$ and $\mathrm{Na}^{+}$ influx. Dev. Biol. 106: 89-96.

Bixby, J. L., R. S. Pratt, J. Lilien, and L. F. Reichardt (1987) Neurite outgrowth on muscle cell surfaces involves extracellular matrix receptors as well as $\mathrm{Ca}^{2+}$-dependent and -independent cell adhesion molecules. Proc. Natl. Acad. Sci. USA 84: 2555-2559.

Bray, D. (1970) Surface movements during the growth of single explanted neurons. Proc. Natl. Acad. Sci. USA 65: 905-910.

Bunge, M. B. (1977) Initial endocytosis of peroxidase or ferritin by growth cones of cultured nerve cells. J. Neurocytol. 6: 407-439.

Caudy, M., and D. Bentley (1986) Pioneer growth cone steering along a series of neuronal and non-neuronal cues of different affinities. $J$. Neurosci. 6: 1781-1795.
Cheng, T. P. O., and T. S. Reese (1987) Recycling of plasmalemma in chick tectal growth cones. J. Neurosci. 7: 1752-1759.

Cohan, C. S., J. A. Connor, and S. B. Kater (1987) Electrically and chemically mediated increases in intracellular calcium in neuronal growth cones. J. Neurosci. 7: 3588-3599.

Connor, J. A. (1986) Digital imaging of free calcium changes and of spatial gradients in growing processes in single mammalian central nervous system cells. Proc. Natl. Acad. Sci. USA 83: 6179-6183.

Conrad, M. J., and S. J. Singer (1981) The solubility of amphipathic molecules in biological membranes and lipid bilayers and its implications for membrane structure. Biochemistry 20:808-818.

DeRiemer, S. A., L. K. Kaczmarek, Y. Lai, T. L. McGuinness, and P. Greengard (1984) Calcium/calmodulin-dependent protein phosphorylation in the nervous system of Aplysia. J. Neurosci. 4: 16181625.

DeRiemer, S. A., P. Greengard, and L. K. Kaczmarek (1985) Calcium/ phosphatidylserine/diacylglycerol-dependent protein phosphorylation in the Aplysia nervous system. J. Neurosci. 5: 2672-2676.

Douglas, W. W. (1968) Stimulus-secretion coupling: The concept and clues from chromaffin and other cells. Br. J. Pharmacol 34: 451-474.

Freeman, J. A., P. B. Manis, G. J. Snipes, B. N. Mayes, P. C. Samson, J. P. Wikswo, Jr., and D. B. Freeman (1985) Steady growth cone currents revealed by a novel circularly vibrating probe: A possible mechanism underlying neurite growth. J. Neurosci. Res. 13: 257-283.

Goldberg, D. J., and D. W. Burmeister (1986) Stages in axon formation: Observations of growth of Aplysia axons in culture using VEC-DIC microscopy. J. Cell Biol. 103: 1921-1931.

Griffin, J. W., D. L. Price, D. B. Drachman, and J. Morris (1981) Incorporation of axonally transported glycoproteins into axolemma during nerve regeneration. J. Cell Biol. 88: 205-214.

Grinvald, A., and I. C. Farber (1981) Optical recording of calcium action potentials from growth cones of cultured neurons with a laser microbeam. Science 212: 1164-1167.

Gunderson, R. W., and J. N. Barrett (1980) Characterization of the turning response of dorsal root neurites toward nerve growth factor. J. Cell Biol. 87: 546-554.

Kapfhammer, J. P., and J. A. Raper (1987) Collapse of growth cone structure on contact with specific neurites in culture. J. Neurosci. 7: 201-212.

Katz, B. (1969) The Release of Neuronal Transmitter Substances, Liverpool U. P., Liverpool.

Katz, F., L. Ellis, and K. H. Pfenninger (1985) Nerve growth cones isolated from fetal rat brain. III. Calcium-dependent protein phosphorylation. J. Neurosci. 5: 1402-1411.

Knight, D. E., and P. F. Baker (1982) Calcium-dependence of catecholamine release from bovine adrenal medullary cells after exposure to intense electric fields. J. Membr. Biol. 68: 107-140.

Letourneau, P. C. (1975a) Possible roles for cell-to-substratum adhesion in neuronal morphogenesis. Dev. Biol. 44: 77-91.

Letourneau, P. C. (1975b) Cell-to-substratum adhesion and guidance of axonal elongation. Dev. Biol. 44: 92-101.

Letourneau, P. C. (1979) Cell-substratum adhesion of neurite growth cones, and its role in neurite elongation. Exp. Cell Res. 124: 127138.

Letourneau, P. C., and A. H. Ressler (1984) Inhibition of neurite initiation and growth by taxol. J. Cell Biol. 98: 1355-1362.

Letourneau, P. C., and N. K. Wessells (1974) Migratory cell locomotion versus nerve axon elongation. Differences based on the effects of lanthanum ion. J. Cell Biol. 61: 56-69.

MacVicar, B. A., and R. R. Llinás (1985) Barium action potentials in regenerating axons of the lamprey spinal cord. J. Neurosci. Res. 13: 323-335.

Meiri, K. F., K. H. Pfenninger, and M. B. Willard (1986) Growthassociated protein, GAP-43, a polypeptide that is induced when neurons extend axons, is a component of growth cones and corresponds to $\mathrm{pp} 46$, a major polypeptide of a subcellular fraction enriched in growth cones. Proc. Natl. Acad. Sci. USA 83: 3537-3541.

Nakazato, Y., and Y. Onoda (1980) Barium and strontium can substitute for calcium in noradrenaline output induced by excess potassium in the guinea-pig. J. Physiol. (Lond.) 305: 59-71.

O'Lague, P. H., S. L. Huttner, C. A. Vandenberg, K. Morrison-Graham, and R. Horn (1985) Morphological properties and membrane channels of the growth cones induced in PC12 cells by nerve growth factor. J. Neurosci. Res. 13: 301-321.

Patel, N. B., and M.-M. Poo (1984) Perturbation of the direction of 
neurite growth by pulsed and focal electric fields. J. Neurosci. 4:29392947.

Pfenninger, K. H., and M.-F. Maylié-Pfenninger (1981) Lectin labeling of sprouting neurons. II. Relative movement and appearance of glycoconjugates during plasmalemmal expansion. J. Cell Biol. 89: 547559.

Schacher, S. (1985) Differential synapse formation and neurite outgrowth at two branches of the metacerebral cell of Aplysia in dissociated cell culture. J. Neurosci. 5: 2028-2034.

Schacher, S., and E. Proshansky (1983) Neurite regeneration by Aplysia neurons in dissociated cell culture: Modulation by Aplysia hemolymph and the presence of the initial axonal segment. J. Neurosci. 3: 2403-2413.

Shapiro, E., V. F. Castellucci, and E. R. Kandel (1980) Presynaptic membrane potential affects transmitter release in an identified neuron in Aplysia by modulating the $\mathrm{Ca}^{2+}$ and $\mathrm{K}^{+}$currents. Proc. Natl. Acad. Sci. USA 77: 629-633.

Sheetz, M. P., and S. J. Singer (1974) Biological membranes as bilayer couples. A mechanism for drug-erythrocyte interactions. Proc. Natl. Acad. Sci. USA 71: 4457-4461.
Silinsky, E. M. (1978) On the role of barium in supporting the asynchronous release of acetylcholine quanta by motor nerve impulses. J. Physiol. (Lond.) 274: 157-171.

Suarez-Isla, B. A., D. J. Pelto, J. M. Thompson, and S. I. Rapoport (1984) Blockers of calcium permeability inhibit neurite extension and formation of neuromuscular synapses in cell culture. Dev. Brain Res. 14: 263-270.

Taghert, P. H., M. J. Bastiani, R. K. Ho, and C. S. Goodman (1982) Guidance of pioneer growth cones: Filopodial contacts and coupling revealed with an antibody to Lucifer yellow. Dev. Biol. 94: 391-399.

von Grafenstein, H., C. S. Roberts, and P. F. Baker (1986) Kinetic analysis of the triggered exocytosis/endocytosis secretory cycle in cultured bovine adrenal medullary cells. J. Cell Biol. 103: 2343-2352.

Weeds, A. (1982) Actin-binding proteins-regulators of cell architecture and motility. Nature 296: 811-816.

Wessells, N. K., M. A. Ludueña, P. C. Letourneau, J. T. Wrenn, and B. S. Spooner (1974) Thorotrast uptake and transit in embryonic glia, heart, fibroblasts, and neurons in vitro. Tissue Cell 6: 757-776. 